\title{
Níveis de Triticale em Substituição ao Milho no Desempenho Zootécnico e Digestibilidade Aparente de Novilhas Nelore Confinadas
}

\author{
Ivanor Nunes do Prado ${ }^{\star}$, Willian Gonçalves do Nascimento², Lúcia Maria Zeoula ${ }^{\star}$, \\ Claudete Regina Alcalde ${ }^{1}$, Sandro Medroni ${ }^{2}$, Karen Vinocur ${ }^{3}$
}

RESUMO - O objetivo deste trabalho foi estudar níveis de substituição do milho pelo triticale em novilhas nelore confinadas. Foram utilizadas 56 novilhas da raça Nelore, com 18 meses de idade e peso vivo médio inicial de $212 \mathrm{~kg}$, distribuídas em um delineamento inteiramente casualizado, com quatro tratamentos $(0,33,66$ e 100\%) de substituição do milho pelo triticale e sete repetições. Não houve efeito dos níveis de substituição do milho pelo triticale sobre o peso vivo final, o ganho médio diário, a ingestão de matéria seca, proteína bruta, fibra em detergente neutro, fibra em detergente ácido e hemicelulose, a conversão alimentar e o rendimento de carcaça. Embora não tenha sido observada diferença em valores absolutos, a ingestão de matéria seca (em $100 \mathrm{~kg}$ de peso vivo) foi crescente entre os níveis 0 e $100 \%$ de triticale. $\mathrm{O}$ mesmo comportamento foi observado para a ingestão de energia bruta (Mcal $/ \mathrm{kg}$ de MS/dia). O ensaio do coeficiente de digestibilidade aparente, com o uso de indicador interno (cinza insolúvel em ácido) e coleta parcial de fezes, demonstrou que não houve diferença na digestibilidade aparente da matéria seca, matéria orgânica, proteína bruta, energia bruta, fibra em detergente neutro, fibra em detergente ácido e hemicelulose. Em função destes resultados, para novilhas confinadas, o triticale poderia ser fonte alternativa viável para substituição ao milho.

Palavras-chave: digestibilidade aparente, ganho em peso, novilhas, triticale

\section{Levels of Triticale in Replacement of Corn on the Performance and Apparent Digestibility of Feedlot Nellore Heifers}

\begin{abstract}
This work was carried out to study the replacement levels of corn by triticale in feedlot Nellore heifers. Fifty-six Nellore heifers, 18 months of age and with an initial LW $212 \mathrm{~kg}$ were allotted to a completely randomized experimental design, with four corn replacement levels $(0,33,66$ and $100 \%)$ by triticale and seven replications. There were no effects of corn replacement levels on the final live weight, average daily gain, intakes of dry matter, crude protein, neutral detergent fiber, acid detergent fiber, hemicellulose (kg/day), feed: gain and carcass yield. Although differences as absolute values have not been registered, the dry matter intake (per 100kg LW) was crescent among 0 to $100 \%$ triticale levels. Similar behavior was observed for the gross energy intake (Mcal/kg of DM/day). The apparent digestibility assay, with the use of an internal indicator (acid insoluble ash) and partial feces collection, demonstrated that there were not differences in the digestibilities of dry matter, organic matter, crude protein, gross energy, neutral detergent fiber, acid detergent fiber and hemicellulose. According to these results triticale may be used by feedlot heifers as a viable alternative source to replace corn.
\end{abstract}

Key Words: apparent digestibility, heifers, triticale, weight gain

\section{Introdução}

O incremento da produção de carne de animais ruminantes pode advir do uso racional de resíduos, subprodutos da agroindústria ou alimentos alternativos ao milho e farelo de soja (PRADO et al., 1995; PETIT et al., 1997). O êxito na exploração intensiva de bovinos de corte está intimamente relacionado à disponibilidade e ao custo dos ingredientes comumente utilizados na alimentação dos animais.

O Brasil apresenta perspectivas favoráveis à produção de grãos que podem ser usados como ingredientes alternativos na alimentação animal, principalmente grãos produzidos no inverno, como é o caso do triticale. Todavia, algumas características do triticale devem ser estudadas antes de sua utilização na alimentação de ruminantes, emfunção de suaalta variabilidade, que é dependente dos cultivares (CHARMLEY et al., 1987; KOCHETOVA et al., 1987; EGGER, 1989; EVERINGTON e GIVENS, 1990; FLACHOWSKY et al., 1991; GOONEWARDENE et al., 1994 e KENNEDY, 1995).

\footnotetext{
* Pesquisador Bolsista CNPq.

${ }^{1}$ Professor do departamento de Zootecnia/UEM-Maringá

2 Pós-graduando em Zootecnia/PPZ/UEM-Maringá

${ }^{3}$ Bolsista de aperfeiçoamento - CNPq.
} 
O triticale é um híbrido transgênico, desenvolvido pelo homem, que possui os genomas completos do trigo Triticum aestivum e do centeio Secale cereale (SOUZA e BAIER, 1982; BAIER, 1995). A designação botânica mais usual é Triticosecale (Wittmack), mas também se usa Triticum turgidicereale (Kiss) Mac Key (OLIVEIRA e BAIER, 1993; BAIER, 1995). O objetivo da combinação desse grão é complementar a rusticidade do centeio com a qualidade do trigo (BAIER et al., 1988).

Algumas variedades ou cultivares de triticale apresentam inibidores de crescimento, conhecidos como inibidores de tripsina. Todavia, existem variedades que não contêm ou têm baixos teores dessas substâncias. As cultivares de triticale cultivados comercialmente no Brasil (Beagle 82, BR-1, BR-2, BR-4) caracterizam-se por baixos teores de inibidores de crescimento (FERREIRA et al., 1991). O efeito desses inibidores é mínimo em ruminantes (Rundgren, 1988, citado por GOONEWARDENE et al., 1994).

CHARMLEY et al. (1987) observaram variações importantes no teor de PB entre diferentes variedades de triticale (10,8 a 19,2\%/MS). Todavia, os teores de MS, FDA, FDN e EB foram semelhantes entre as variedades. KENNEDY (1995) encontrou valores de $87,9-88,7 \%, 13,1-14,2 \%$ e $2,5-3,0 \%$ para a MS, PB e FB, respectivamente, para sete variedades de triticale, em três locais de crescimento diferentes na Inglaterra.

No Brasil, MEDRONI et al. (1998) encontraram $16,5 \%, 14,6 \%, 4,2 \%$ e $4,32 \mathrm{Mcal} / \mathrm{kg}$ de MS para a PB, FDN, FDA e EB, respectivamente.

REDDY et al. (1975) mostraram que o ganho em peso e o consumo de alimentos foram menores para novilhos terminados em confinamento (107 dias) e alimentados com triticale em comparação aos animais alimentados com milho ou trigo. Todavia, em ensaios de 84 dias de confinamento de bovinos, HILL e UTLEY $(1986,1988)$ não observaram diferenças no consumo de alimentos, na conversão alimentar e no ganho em peso, em comparação ao milho.

CHARMLEY et al. (1987) não observaram diferenças para a digestibilidade aparente da MS, MO, FDN e EB, entre o farelo de trigo e três variedades de triticale, em ovinos. Todavia, para determinada variedade (PBI121), a digestibilidade aparente da PB foi menor, o que pode ser atribuído ao menor teor de PB nesta variedade. Resultados maiores para a digestibilidade aparente da $\mathrm{PB}$, em relação ao trigo, foram observados por KOCHETOVA et al. (1987). EGGER et al. (1989) não verificaram diferenças na digestibilidade aparente da MS do farelo de centeio e triticale em ruminantes.

EVERINGTON e GIVENS (1990) não observaram efeito da variedade do triticale sobre a digestibilidade aparente da MO, PB, EE e EB, em ovinos. NASCIMENTO e PRADO (1998) observaram maiores taxas de desaparecimento ruminal da MS e PB de rações contendo triticale e levedura desidratada, em relação ao milho e farelo de soja, em vacas portadoras de cânulas de rúmen. Todavia, para a fração FDN, não foram observadas diferenças na degradabilidade, em razão, talvez, do baixo teor de FDN nos alimentos comparados. Rações contendo milho ou triticale, em combinação com farelo de soja ou levedura, não influíram na digestibilidade aparente, estimada com cinza insolúvel em ácido, da MS, MO, PB, EB, FDN e FDA, em rações fornecidas para novilhas Nelore, nas fases de crescimento e terminação (MEDRONI et al., 1999).

O objetivo deste trabalho foi estudar a viabilidade da substituição parcial e total do milho pelo triticale na alimentação de novilhas Nelore confinadas durante 84 dias sobre o desempenho animal e a digestibilidade aparente.

\section{Material e Métodos}

O trabalho foi realizado na Fazenda Experimental de Iguatemi (FEI), no Setor de Bovinocultura de Corte, pertencente à Universidade Estadual de Maringá(UEM). As análises foram realizadas no Laboratório de Nutrição Animal do Departamento de Zootecnia (DZO).

Foram utilizadas 56 novilhas da raça Nelore, com idade e peso médios de, respectivamente, 18 meses e $212 \mathrm{~kg}$. Antes do período de adaptação, os animais foram tratados contra endo e ectoparasitas, vacinados contra febre aftosa, identificados com brincos plásticos e alojados dois a dois em baias de $10 \mathrm{~m}^{2}$. As baias eram cercadas de cordoalhas de aço, com piso de concreto, sendo metade da baia coberta com telhas de zinco, com bebedouros de 250 litros, localizados na área descoberta e comedouros, construídos em alvenaria, na área coberta com 2 metros lineares/baia. As baias foram limpas três vezes por semana ou de acordo com as necessidades.

O experimento avaliou quatro tratamentos: 0,33 , 66 ou $100 \%$ de triticale em substituição ao milho, como fonte de energia. A silagem de milho foi usada como volumoso. A levedura desidratada de cana-deaçúcar e o farelo de soja foram usados como fonte de proteína. Bicarbonato de sódio, monensina, uréia, 
Rev. bras. zootec.

calcário e sal mineral foram usados como complementos (Tabela 1). O uso da uréia se fez necessário para tornar as rações isoprotéicas.

As rações completas (volumoso + concentrado) foram fornecidas nos comedouros pela manhã $(8 \mathrm{~h}) \mathrm{e}$ à tarde $(16 \mathrm{~h})$. As sobras do dia anterior foram retiradas e pesadas, para controle de consumo e amostradas (5\%). Água limpa foi fornecida ad libitum durante todo o experimento.

Os animais foram pesados no início do experimento e, posteriormente, a cada 28 dias. O experimento teve duração de 84 dias. As pesagens foram efetuadas pela manhã, com período de jejum de ração de 14 horas. O consumo de água foi permitido até o momento de embarque dos animais. Ao final do experimento, os animais foram conduzidos a um frigorífico da região para abate e determinação do peso e rendimento de carcaça quente.

Os alimentos foram amostrados separadamente para as análises laboratoriais. As amostras parciais, coletadas semanalmente, foram acondicionadas em sacos plásticos individuais, identificados por trata- mento, baia e número do animal, sendo armazenadas sob congelamento $\left(-20^{\circ} \mathrm{C}\right)$. Nas análises posteriores, as amostras parciais formaram uma amostra composta por tratamento.

O ensaio de digestibilidade foi realizado concomitantemente ao desenvolvimento do experimento de desempenho. A coleta de dados teve duração de sete dias, respeitando-se um período de 28 dias de adaptação. Foram coletadas amostras diárias das sobras e fezes em cada baia. As coletas foram realizadas, logo após a defecação dos animais, no piso de concreto, com uso de uma colher de haste longa.

As composições químicas (\% da MS) dos alimentos usados, assim como das rações experimentais, estão apresentadas na Tabela 1 e a composição percentual das rações experimentais, na Tabela 2.

Nos alimentos, nas sobras e fezes, foram determinados os teores de matéria seca (MS), matéria orgânica (MO), cinzas, proteína bruta (PB), energia bruta (EB), fibra em detergente neutro (FDN) e fibra em detergente ácido (FDA), segundo o esquema convencional de Weende e o Método de Partição de

Tabela 1 - Composição química (\%/MS) dos ingredientes e das rações experimentais*

Table 1 - Chemical composition (\%/DM) of the ingredients and of the experimental diets*

\begin{tabular}{|c|c|c|c|c|c|c|c|c|}
\hline $\begin{array}{l}\text { Ingrediente } \\
\text { Ingredient }\end{array}$ & $\begin{array}{l}\text { MS } \\
D M\end{array}$ & $\begin{array}{l}\mathrm{PB} \\
C P\end{array}$ & $\begin{array}{l}\mathrm{MO} \\
O M\end{array}$ & $\begin{array}{c}\mathrm{EB}^{\#} \\
G E\end{array}$ & $\begin{array}{l}\mathrm{FDN} \\
N D F\end{array}$ & $\begin{array}{l}\text { FDA } \\
A D F\end{array}$ & $\begin{array}{l}\text { HEM } \\
H E M\end{array}$ & $\begin{array}{c}\text { Cinzas } \\
\text { Ashes }\end{array}$ \\
\hline $\begin{array}{l}\text { Silagem de milho } \\
\text { Corn silage }\end{array}$ & 36,48 & 6,11 & 95,59 & 4,31 & 59,37 & 33,05 & 26,32 & 4,41 \\
\hline $\begin{array}{l}\text { Farelo de soja } \\
\text { Soybean meal }\end{array}$ & 88,62 & 51,89 & 93,03 & 4,70 & 18,08 & 11,10 & 6,97 & 6,97 \\
\hline $\begin{array}{l}\text { Levedura } \\
\text { Yeast }\end{array}$ & 94,17 & 39,55 & 92,01 & 4,47 & & & & 7,99 \\
\hline $\begin{array}{l}\text { Milho } \\
\text { Ground corn }\end{array}$ & 89,11 & 10,73 & 98,96 & 4,32 & 12,64 & 3,11 & 9,53 & 1,04 \\
\hline $\begin{array}{l}\text { Triticale } \\
\text { Triticale }\end{array}$ & 87,68 & 11,80 & 98,57 & 4,31 & 14,43 & 4,04 & 10,39 & 1,43 \\
\hline $\begin{array}{l}\text { Uréia } \\
\text { Urea }\end{array}$ & 72,27 & 384,20 & 99,83 & - & - & - & - & 0,17 \\
\hline $\begin{array}{l}\text { Calcário } \\
\text { Limestone }\end{array}$ & 99,99 & - & 0,46 & - & - & - & - & 99,54 \\
\hline $\begin{array}{l}\text { Sal mineral } \\
\text { Mineral salt }\end{array}$ & 96,59 & - & 10,71 & - & - & - & - & 89,29 \\
\hline $\begin{array}{l}\text { Bicarbonato de sódio } \\
\text { Sodium bicarbonate }\end{array}$ & 96,96 & - & - & - & - & - & - & - \\
\hline $\begin{array}{l}\text { Monensina } \\
\text { Monensin }\end{array}$ & 90,84 & - & - & - & - & - & - & - \\
\hline $\begin{array}{l}\text { Tratamentos } \\
\text { Treatments }\end{array}$ & $\begin{array}{l}\text { MS } \\
D M\end{array}$ & $\begin{array}{l}\mathrm{PB} \\
C P\end{array}$ & $\begin{array}{l}\mathrm{MO} \\
\mathrm{OM}\end{array}$ & $\begin{array}{c}\mathrm{EB}^{\#} \\
G E\end{array}$ & $\begin{array}{l}\text { FDN } \\
N D F\end{array}$ & $\begin{array}{l}\text { FDA } \\
A D F\end{array}$ & $\begin{array}{l}\text { HEM } \\
H E M\end{array}$ & $\begin{array}{c}\text { Cinzas } \\
\text { Ash }\end{array}$ \\
\hline $\begin{array}{l}00 \% \\
33 \% \\
66 \% \\
100 \%\end{array}$ & $\begin{array}{l}47,61 \\
47,67 \\
47,76 \\
47,86\end{array}$ & $\begin{array}{l}14,20 \\
14,12 \\
14,04 \\
13,96\end{array}$ & $\begin{array}{l}94,55 \\
94,58 \\
94,58 \\
94,60\end{array}$ & $\begin{array}{l}4,28 \\
4,28 \\
4,29 \\
4,30\end{array}$ & $\begin{array}{l}40,85 \\
40,87 \\
40,91 \\
40,81\end{array}$ & $\begin{array}{l}21,90 \\
21,91 \\
21,95 \\
21,90\end{array}$ & $\begin{array}{l}18,94 \\
18,96 \\
18,95 \\
18,91\end{array}$ & $\begin{array}{l}5,45 \\
5,42 \\
5,42 \\
5,40\end{array}$ \\
\hline
\end{tabular}

\#Mcal $/ \mathrm{kg}$ de MS (\#Mcal/kg of DM). 
1548

Tabela 2 - Composição percentual (\%/MS) das rações experimentais

Table 2 - Percentage composition of the experimental (\%/DM) of diets

\begin{tabular}{|c|c|c|c|c|}
\hline \multirow[t]{2}{*}{$\begin{array}{l}\text { Ingrediente } \\
\text { Ingredient }\end{array}$} & \multirow{2}{*}{\multicolumn{4}{|c|}{$\begin{array}{l}\text { Níveis de triticale (\%) } \\
\text { Levels of triticale (\%) }\end{array}$}} \\
\hline & 0 & & & 100 \\
\hline $\begin{array}{l}\text { Silagem de milho } \\
\text { Corn silage }\end{array}$ & 60,41 & 60,17 & 59,88 & 59,56 \\
\hline $\begin{array}{l}\text { Farelo de soja } \\
\text { Soybean meal }\end{array}$ & 10,67 & 10,83 & 11,51 & 11,44 \\
\hline $\begin{array}{l}\text { Levedura } \\
\text { Yeast }\end{array}$ & 2,84 & 3,04 & 3,23 & 3,98 \\
\hline $\begin{array}{l}\text { Milho } \\
\text { Ground corn }\end{array}$ & 24,15 & 16,17 & 7,98 & - \\
\hline $\begin{array}{l}\text { Triticale } \\
\text { Triticale }\end{array}$ & - & 7,95 & 15,70 & 23,42 \\
\hline $\begin{array}{l}\text { Uréia } \\
\text { Urea }\end{array}$ & 0,33 & 0,25 & 0,11 & 0,01 \\
\hline $\begin{array}{l}\text { Calcário } \\
\text { Limestone }\end{array}$ & 0,60 & 0,60 & 0,60 & 0,59 \\
\hline $\begin{array}{l}\text { Sal mineral } \\
\text { Mineral salt }\end{array}$ & 0,58 & 0,58 & 0,58 & 0,57 \\
\hline $\begin{array}{l}\text { Bicarbonato de sódio } \\
\text { Sodium bicarbonate }\end{array}$ & 0,40 & 0,40 & 0,40 & 0,40 \\
\hline $\begin{array}{l}\text { Monensina } \\
\text { Monensin }\end{array}$ & 0,02 & 0,02 & 0,02 & 0,02 \\
\hline
\end{tabular}

* Dados do Laboratório de Análise de Alimentos e Alimentação e Nutrição Animal - DZO/UEM. "Mcal/kg de MS.

Data obtained from the Laboratory of Feed Analyses and Animal Nutrition,

${ }^{\#}$ Mcal $/ \mathrm{kg}$ of DM.

Fibras (Método de Van Soest), conforme SILVA (1990). Ainda, para determinação do cálculo dos coeficientes de digestibilidade aparente, o fluxo da matéria seca fecal foi determinado por intermédio do indicador interno cinza insolúvel em ácido (CIA), segundo VAN KEULEN e YOUNG (1977).

Os coeficientes de digestibilidade aparente da matéria seca e demais nutrientes foram determinados conforme descrito abaixo:

Coeficiente de digestibilidade aparente da matéria seca (CDAMS)

CDAMS $=100-100 \times \frac{\% \text { Indicador no alimento }}{\% \text { Indicador nas fezes }}$

Coeficiente de digestibilidade aparente dos nutrientes (CDAN)

$\mathrm{CDAN}=100-100 \times(\%$ na MS do alimento $\times$ \% nutrientes nas fezes $)$ (\% ind. na MS das fezes \% nutr. no alimento)

Os dados do desempenho zootécnico foram analisados por intermédio do programa Sistema de análises estatísticas e genéticas - SAEG (EUCLYDES,
1983). O delineamento experimental utilizado foi o inteiramente casualizado, com quatro tratamentos e sete repetições, sendo as variáveis analisadas de acordo com o seguinte modelo matemático:

$$
\mathrm{Y}_{i j}=\mu+\mathrm{T}_{i}+\mathrm{b}_{1}(\mathrm{PI}-\mathrm{PIm})+\mathrm{e}_{i j}
$$

$\mathrm{Y}_{i j}=$ observação do desempenho do animal $j$, que recebeu o tratamento $i$;

$\mu=$ constante comum a todas as observações;

$\mathrm{T}_{i}=$ efeito do tratamento $i$, sendo $i=1,2,3,4$;

$\mathrm{b}_{1}=$ coeficiente linear de regressão de $\mathrm{Y}$ com o peso inicial (PI);

$\mathrm{PI}=$ peso inicial;

$\mathrm{PIm}=$ peso inicial médio;

$\mathrm{e}_{i j}=$ erro aleatório associado a cada observação do desempenho $\mathrm{Y}_{i j}$.

Os dados de digestibilidade aparente e rendimento de carcaça foram analisados por meio do programa SAEG (EUCLYDES, 1983). O delineamento experimental utilizado foi o inteiramente casualizado, com quatro tratamentos e sete repetições, em que as variáveis foram analisadas de acordo com o seguinte modelo matemático:

$$
\mathrm{Y}_{i j}=\mu+\mathrm{T}_{i}+\mathrm{e}_{i j}
$$

$\mathrm{Y}_{i j}=$ observação referente a digestibilidade do tratamento $i$ do animal $j$;

$\mu=$ constante comum a todas as observações;

$\mathrm{T}=$ efeito do tratamento $i$, sendo $i=1,2,3,4$;

$\mathrm{e}_{i j}=$ erro aleatório associado a cada observação da digestibilidade $\mathrm{Y}_{i j}$.

\section{Resultados e Discussão}

Independentemente dos níveis $(0,33,66$ e 100\%) de substituição do milho pelo triticale na ração de novilhas confinadas, não houve diferença para peso final, ganho médio diário (GMD), ingestão (kg/dia) de matéria seca (IMS), proteína bruta (IPB), fibra em detergente neutro (IFDN), fibra em detergente ácido (IFDA) e hemicelulose (IHEM), conversão da matéria seca (CMS) e rendimento de carcaça (RC) (Tabela 3). Embora, não tenham sido observadas diferenças $(\mathrm{P}>0,05)$, em valores absolutos, na IMS ( $\mathrm{kg} / \mathrm{dia})$ e IEB (Mcal $/ \mathrm{kg}$ de MS/dia), constatou-se efeito linear $(\mathrm{P}<0,05)$ da IMS $(\mathrm{y}=2,96+0,0014 \mathrm{t})$ (Figura 1) e IEB ( $\mathrm{y}=4,28+0,00014 \mathrm{t}$ ) (Figura 2), em relação a $100 \mathrm{~kg}$ de peso vivo. $\mathrm{O}$ aumento linear, em função da substituição do milho pelo triticale na IMS e IEB, em relação ao peso vivo, poderia ser explicado pelos combinações entre a IMS e o GMD.

Em trabalho desenvolvido por REDDY et al. 
Regressão linear da ingestão de matéria seca Linear regressin of dry matter intake

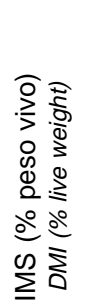

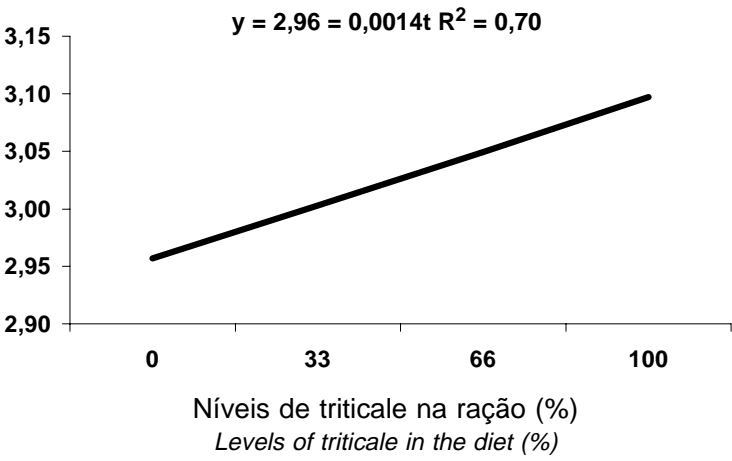

Figura 1 - Efeito dos níveis de substituição do milho pelo triticale sobre a ingestão de matéria seca (IMS) (\% peso vivo).

Figure 1 - Effects of the levels of corn replacement by triticale on dry matter intake (DMI) (\% live weight).

(1975), foi observada redução no GMD e na ingestão alimentar de novilhos terminados em confinamento e alimentados com triticale em comparação aos animais alimentados com milho. As divergências encontrados poderiam estar relacionadas às variedades de triticale usadas. No entanto, HILL e UTLEY (1986, 1988) não observaram diferenças no GMD, no consumo e na conversão alimentar, com substituição total do milho pelo triticale, em novilhos terminados em confinamento. Da mesma forma, JAHN et al. (1989) não verificaram diferenças no ganho em peso com a substituição de 25,50 e $100 \%$ do milho pelo triticale para bezerros holandeses. Ainda, HILL e UTLEY (1989) observaram ganhos em peso e conversão alimentar similares em novilhas alimentadas com $70 \%$ de milho ou $50 \%$ de milho $+50 \%$ de triticale ou cevada. Resultados semelhantes para ganho em peso, consumo e conversão alimentar foram observados por ZOBELL et al. (1990), em novilhas de $280 \mathrm{~kg}$ de peso vivo, confinadas por 120 dias e alimentadas com $100 \%$ de cevada ou $100 \%$ de triticale. Este resultados foram confirmados em machos inteiros, terminados em confinamento, recebendo como fonte de energia cevada, centeio ou triticale. A inclusão de $77 \%$ de triticale no concentrado de bovinos em fase de terminação resultou em menor consumo de MS e ganho em peso $(9,4$ e 1,3 kg/dia) em comparação à cevada (10,5 e $1,5 \mathrm{~kg} / \mathrm{dia}$ ), sendo que a conversão alimentar não foi alterada (GOONEWARDENE et al., 1994). Os autores concluíram que o menor consumo e ganho em peso dos animais, com o triticale na ração, resultaram do maior período de tempo para adaptação. Por outro lado, MEDRONI et al. (1998) não observaram dife- renças no consumo, na conversão alimentar e no rendimento de carcaça (53\%), em novilhas Nelore, terminadas em confinamento ( 84 dias), com $235 \mathrm{~kg}$ de peso inicial e 18 meses de idade, recebendo $100 \%$ de triticale na ração, em substituição ao milho. Todavia, o GMD foi maior para ração com triticale $(1,3 \mathrm{~kg})$, em comparação ao milho $(1,2 \mathrm{~kg})$. Os autores atribuíram o maior ganho em peso com o triticale ao efeito interativo das rações, uma vez que a mesma continha, como volumoso, silagem de milho e proporção concentrado volumoso de 35:65 da MS. Dessa forma, os resultados encontrados neste experimento estão de acordo com a maior parte dos trabalhos encontrados na literatura, confirmando, assim, a possibilidade de substituir o milho pelo triticale para animais confinados, sem alterar o ganho em peso e consumo de alimentos.

O rendimento de carcaça (Tabela 3) foi similar entre tratamentos $(53,5 \%)$. Rendimento de carcaça desta ordem de grandeza pode ser considerado satisfatório para animais desta categoria. Rendimento semelhante, $53 \%$, foi encontrado por MEDRONI et al. (1998), para novilhas da mesma categoria, em condições semelhantes de manejo e alimentação. Pequenas diferenças podem ser atribuídas ao local de abate, em função da limpeza ou toalete das carcaças, que podem chegar a $5 \%$ do peso da carcaça.

Os níveis de substituição do milho pelo triticale $(0$, 33,66 e 100\%) não influenciaram o coeficiente de digestibilidade aparente da matéria seca (CDMS), matéria orgânica (CDMO), proteína bruta (CDPB), energia bruta (CDEB), fibra em detergente neutro

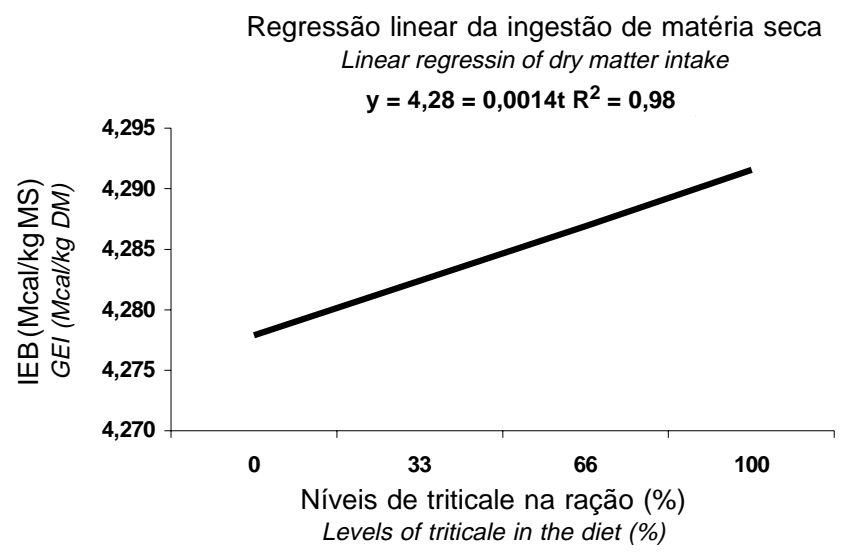

Figura 2 - Efeito dos níveis de substituição do milho pelo triticale sobre a ingestão de energia bruta (IEB) (Mcal/kg de MS).

Figure 2 - Effects corn replacement levels by triticale on feed intake of gross energy (GEI) (Mcal/kg of the DM). 
PRADO et al.

Tabela 3 - Efeito dos níveis de substituição do milho pelo triticale sobre o peso inicial $(\mathrm{PI})$, peso final $(\mathrm{PF})$, ganho médio diário $(\mathrm{GMD})$, ingestão $(\mathrm{kg} / \mathrm{dia})$ de matéria seca (IMS), proteína bruta (IPB), fibra em detergente neutro (IFDN), fibra em detergente ácido (IFDA) e hemicelulose (IHEM), conversão alimentar (CA) e rendimento de carcaça $(\mathrm{RC})$ de novilhas Nelore

Table 3 - Effects corn replacement levels by triticale on initial weight (IW), final weight (FW), average daily gain (ADG), intake ( $\mathrm{kg} /$ day) of dry matter (DMI), crude protein (CPI), neutral detergent fiber (NDFI), acid detergent fiber (ADFI) and hemicellulose (HEMI) and feed:gain ratio (F/G) and carcass yield $(C Y)$ in Nellore heifers

\begin{tabular}{|c|c|c|c|c|c|c|}
\hline \multirow[b]{3}{*}{$\begin{array}{l}\text { Parâmetros } \\
\text { Parameters }\end{array}$} & \multicolumn{4}{|c|}{ Níveis de triticale (\%) } & \multirow[b]{3}{*}{$\begin{array}{l}\text { Média } \\
\text { Mean }\end{array}$} & \multirow[b]{3}{*}{$\mathrm{CV}(\%)^{*}$} \\
\hline & \multicolumn{4}{|c|}{ Levels of triticale (\%) } & & \\
\hline & 0 & 33 & 66 & 100 & & \\
\hline $\begin{array}{l}\mathrm{PI}(\mathrm{kg}) \\
I W(k g)\end{array}$ & 214,4 & 220,9 & 207,7 & 205,4 & 212,1 & 8,9 \\
\hline $\begin{array}{l}\mathrm{PF}(\mathrm{kg}) \\
F W(\mathrm{~kg})\end{array}$ & 315,3 & 316,8 & 305,1 & 297,5 & 308,7 & 8,5 \\
\hline $\begin{array}{l}\operatorname{GMD}(\mathrm{kg}) \\
D G M K G)\end{array}$ & 1,2 & 1,1 & 1,2 & 1,1 & 1,2 & 13,0 \\
\hline $\begin{array}{l}\text { IMS (kg/dia }) \\
D M I(\mathrm{~kg} / \text { day })\end{array}$ & 7,8 & 8,0 & 7,9 & 7,7 & 7,9 & 7,2 \\
\hline $\begin{array}{l}\text { IPB ( } \mathrm{kg} / \mathrm{dia}) \\
C P I(\mathrm{~kg} / \text { day })\end{array}$ & 1,2 & 1,2 & 1,1 & 1,1 & 1,1 & 6,2 \\
\hline $\begin{array}{l}\text { IFDN ( } \mathrm{kg} / \text { dia }) \\
N D F I \text { (kg/day) }\end{array}$ & 3,2 & 3,3 & 3,2 & 3,2 & 3,2 & 7,6 \\
\hline $\begin{array}{l}\text { IFDA (kg/dia) } \\
A D F I \text { (kg/day) }\end{array}$ & 1,7 & 1,8 & 1,7 & 1,7 & 1,7 & 7,8 \\
\hline $\begin{array}{l}\operatorname{IHEM}(\mathrm{kg} / \text { dia }) \\
\text { HEMI }(\mathrm{kg} / \text { day })\end{array}$ & 2,2 & 2,0 & 1,8 & 1,5 & 1,9 & 5,8 \\
\hline $\begin{array}{l}\text { CA } \\
F / G\end{array}$ & 6,7 & 7,4 & 7,1 & 7,2 & 7,1 & 10,9 \\
\hline $\begin{array}{l}\mathrm{RC}(\%) \\
C Y(\%)\end{array}$ & 53,0 & 54,0 & 53,4 & 53,4 & 53,5 & 3,1 \\
\hline
\end{tabular}

${ }^{*}$ Coeficiente de variação (Coefficient of variation).

(CDFDN), fibra em detergente ácido (CDFDA) e hemicelulose (CDHEM) (Tabela 4).

O CDMS médio $(63,2 \%)$ das quatro dietas foi semelhante aos resultados obtidos por animais de mesma idade e categoria animal (MEDRONI etal., 1999).

O CDMO médio $(65,6 \%)$ dos quatro tratamentos foi superior ao dados obtidos por MEDRONI et al. (1999), de $61,13 \%$, possivelmente porque rações com teores elevados de PB podem favorecer a digestão ruminal da matéria orgânica. Segundo TAMMINGA (1996), a digestibilidade pode ser aumentada com melhor controle dos fatores determinantes da digestão dos alimentos, como por exemplo a poder interativo dos mesmos. Desse modo, sincronização entre proteínas e carboidratos também diminuiria as perdas de nitrogênio do rúmen. A utilização dos compostos da parede celular exige interação dinâmica entre o animal, a população microbiana e a dieta (NOCEK, 1988).
O CDPB médio $(59,8 \%)$ das quatro dietas pode ser explicado pelo teor de $14 \%$ de PB nas dietas experimentais. Dietas com elevado teor de PB poderiam proporcionar menor digestibilidade da mesma (PETIT e TREMBLAY, 1992). VALADARES et al. (1997), trabalhando com vários níveis de proteína em dietas de novilhos zebuínos, concluíram que rações com aproximadamente $11 \%$ de PB promoveram maior eficiência microbiana para dietas com $45 \%$ de concentrado.

O CDEB médio $(63,5 \%)$ foi semelhante aos encontrados por MEDRONI et al. (1998), 63,6\%, que avaliaram dietas à base de milho ou triticale $\mathrm{e}$ farelo de soja ou levedura, em novilhas Nelore em confinamento.

A digestibilidade da FDN apresentou resultado médio de $57,77 \%$, sendo maior aos obtidos por PINHEIRO (2000), de 49,38\%. Todavia, vale salientar que esse autor, apesar de ter trabalhado em 
Rev. bras. zootec.

Tabela 4 - Efeito dos níveis de substituição do milho pelo triticale sobre o coeficiente de digestibilidade aparente da matéria seca (CDMS), matéria orgânica (CDMO), proteína bruta (CDPB), energia bruta (CDEB), fibra em detergente neutro (CDFDN), fibra em detergente ácido (CDFDA) e hemicelulose (CDHEM) em novilhas Nelore confinadas

Table 4 - Effects corn replacement levels by triticale on apparent digestibility coefficient of the dry matter (CDDM), organic matter (CDOM), crude protein $(C D C P)$, gross energy (CDGE), neutral detergent fiber (NDF), acid detergent fiber (CDADF) and hemicellulose (CDHEM) in feedlot Nellore heifers

\begin{tabular}{|c|c|c|c|c|c|c|}
\hline & & veis de & ticale ( & & & \\
\hline & & vels of & ticale & & & \\
\hline $\begin{array}{l}\text { Parâmetros } \\
\text { Parameters }\end{array}$ & 0 & 33 & 66 & 100 & $\begin{array}{l}\text { Média } \\
\text { Mean }\end{array}$ & $\mathrm{CV}(\%)^{*}$ \\
\hline $\begin{array}{l}\text { CDMS } \\
C D D M\end{array}$ & 66,13 & 60,29 & 63,54 & 63,02 & 63,24 & 9,82 \\
\hline $\begin{array}{l}\text { CDMO } \\
\text { CDOM }\end{array}$ & 68,22 & 62,82 & 65,81 & 65,40 & 65,56 & 9,02 \\
\hline $\begin{array}{l}\text { CDPB } \\
C D C P\end{array}$ & 62,91 & 55,12 & 60,66 & 60,46 & 59,79 & 11,25 \\
\hline $\begin{array}{l}\text { CDEB } \\
C D G E\end{array}$ & 65,85 & 60,16 & 64,01 & 63,91 & 63,48 & 9,59 \\
\hline $\begin{array}{l}\text { CDFDN } \\
C D N D F\end{array}$ & 61,57 & 54,22 & 58,34 & 56,93 & 57,77 & 11,74 \\
\hline $\begin{array}{l}\text { CDFDA } \\
C D A D F\end{array}$ & 65,89 & 60,13 & 63,79 & 63,17 & 63,24 & 10,01 \\
\hline $\begin{array}{l}\text { CDHEM } \\
\text { CDHEM }\end{array}$ & 53,96 & 43,67 & 48,23 & 43,39 & 47,31 & 24,34 \\
\hline
\end{tabular}

${ }^{*}$ Coeficiente de variação (Coefficient of variation).

condições semelhantes, observou grande variação nos resultados encontrados na digestibilidade, o que pode ser explicado pela dificuldade ainda encontrada com o uso do indicador.

\section{Conclusões}

A substituição parcial ou total do milho pelo triticale, como fonte de energia, não alterou peso final, ganho médio diário, ingestão e conversão alimentar, rendimento de carcaça e coeficiente de digestibilidade aparente em novilhas Nelore confinadas, durante 84 dias. Dessa forma, para animais terminados em confinamento, o triticale poderia ser fonte alternativa viável, em substituição ao milho.

\section{Referências Bibliográficas}

BAIER, A.C., SOUZA, P.G., BOLDT, A.F. 1988. Potencial do triticale no Mato Grosso do Sul. Comunicado Técnico UEPAE, 37:7-17.

BAIER, A. C. Potencialidade do triticale no Brasil. In: REUNIÃO BRASILEIRA DE TRITICALE, 5, 1995, Chapecó. Anais... Chapecó: Santa Catarina., 1995, p.8-23.

CHARMLEY, E., GREENHALE, H. 1987. Nutritive value of three cultivars of triticale for sheep, pigs and poultry. Anim. Feed Sci. Techon., 18(11):19-35.
EGGER, I. 1989. The nutrient value of triticale as a feedstuff Landwirt. Schweiz, 2(8):491-495.

EUCLYDES, R.F. 1983. Sistema de análises estatísticas e genéticas - SAEG. Central de Processamento de Dados. Viçosa, MG: UFV. 68p. (Manual do usuário).

EVERINGTON, J.M., GIVENS, D.I. 1990. Nutritive value of whole triticale grain for sheep. Anim. Feed Sci. Techn., 30(1-2):163-168.

FERREIRA, A.S., LIMA, G.J.M.M., GOMES, M.F.M. et al. 1991. Triticale na alimentação de suínos. Comunicado Técnico - EMBRAPA - CNPSA, v.165. p.1-3.

FLACHOWSKY, G., SCHNEIDER, M., KOCH, H. 1991. Comparative studies on the feeding value of rye, wheat and triticale in sheep and cattle. Umwelt. der Tierprod. 103. VDLUFA Kongress, 16-21(33):808-813.

GOONEWARDENE, L.A., ZOBELL, D.R., BASARAB, J.A. 1994. Comparasion of growth and feed efficiency of steers fed barley and triticale diets. Can. J. Anim. Sci., 74(1):159-161.

HILL, G.M., UTLEY, P.R. 1986. Comparative nutritional value of Beagle 82 triticale for finishing steers. Nutr. Rep. Intern., 34:831-840

HILL, G.M., UTLEY, P.R. 1988. Beagle 82 triticale and Kline barley digestibility and utilization by cattle. J. Anim. Sci., 66:474(Abstr.) (suppl. 1).

HILL, G.M., UTLEY, P.R. 1989. Digestibility, protein metabolism and ruminal degradation of Beagle 82 triticale and kline barley fed in ground corn-based cattle diets. J. Anim. Sci., 67(7):1793-1804.

JAHN, B.C., VIDAL, V.A., BONILLA, E.W. et al. 1989. Evaluation of triticale in diets for ruminants. Agr. Tec. Santiago, 49(3):216-219. 
KENNEDY, D. 1995. Evaluation of nutritional characteristics of triticale varieties. Nutr. Abst. and Rev. (serie B), 65(10):723.

KOCHETOVA, A., LEVITSKII, A., FEDOROVA, T. 1987. Tricale. Nutr. Abst. and Rev., 57(3):936.

MEDRONI, S., PRADO, I.N., NASCIMENTO, W.G. et al. Efeito da combinação de dietas com milho ou triticale e farelo de soja ou levedura no consumo de novilhas nelore confinadas. In: REUNIÃO ANUAL DA SOCIEDADE BRASILEIRA DE ZOOTECNIA, 1998, Botucatu. Anais... Botucatu: UNESP, 1998. p.620-622.

MEDRONI, S., PRADO, I.N., ZEOULA, L.M. et al. 1999. Digestibilidade "in vivo" de dietas combinadas contendo milho ou triticale e farelo de soja ou levedura em novilhas nelore confinadas. Acta Scientiarum, 21(3):345-649

NASCIMENTO, W.G., PRADO, I.N. Degradabilidade ruminal "in situ" de dietas compostas com milho ou triticale e farelo de soja ou levedura. In: ENCONTRO ANUAL DE INICIAÇÃO CIENTÍFICA PIBIC/CNPq, 7, 1998, Maringá. Anais... Maringá: UEM, 1998. p.626.

NOCEK, J.E. 1988. Production research papers. J. Dairy Sci., 71(8):2051-2069.

OLIVEIRA, A.M.R., BAIER, A.C. 1993. Qualidade industrial e resistência à helmintosporiose e à fusariose em triticale, trigo e centeio. Pesq. Agrop. Bras., 28(5):603-608.

PETIT, H.V., RIOUX, R., D'OLIVEIRA, PRADO, I.N. 1997. Performance of growing lambs fed grass silage with raw or extruded soybean or canola seeds. Can. J. Anim. Sci., 77(1):455-463.

PETIT, H.V., TREMBLAY, G.F. 1992. "In situ" degradability of fresh grass and grass conserved under different harvesting methodes. J. Dairy Sci., 75(4):774-781.

PINHEIRO, A.D. Níveis de substituição do milho pela polpa de citrus peletizada sobre o desempenho, característica de carcaça e digestibilidade em bovinos mestiços confinados. Maringá, PR: UEM, 2000. 40p. Dissertação (Mestrado em Zootecnia) - Universidade Estadual de Maringá, 2000.
PRADO, I.N., BRANCO, A.F., ZEOULA, L.M. et al. 1995. Desempenho e características de carcaça de bovinos nelore confinados, recebendo 15 ou $30 \%$ de caroço de algodão, bagaço auto-hidrolisado de cana-de-açúcar ou capim elefante. Arq. Biol. Tecnol., 38(2):353-365.

REDDY, S.G., CHEN, M.L., RAO, D.R. 1975. Replacement value of triticale for corn and wheat in beef finishing rations. J. Anim. Sci., 40:940-946.

SILVA, D. J. 1990. Análise de alimentos - métodos químicos e biológicos. 2 ed., Viçosa: Imprensa Universitária. 166p.

SOUZA, P.G., BAIER, A.C. 1982. Comportamento de linhagens de triticale em Dourados, MS. Comunicado Técnico EMBRAPA, Dourados, v.9. p.1-11.

TAMMINGA, S. 1996. A review on enviromental impacts of nutritional strategies in ruminants. J. Anim. Sci., 74(2):3112-3124.

VALADARES, R.F.D., GONÇALVES, L.C., VALADARES FILHO, S.C. et al. Níveis de proteína em dietas de bovinos. 3. pH, amônia e eficiência microbiana. In: REUNIÃO ANUAL DA SOCIEDADE BRASILEIRA DE ZOOTECNIA, 34, 1997. Juiz de Fora. Anais... Juiz de Fora, 1997, p.46-48.

VAN KEULEN, J., YOUNG, B. A. 1977. Evaluation of acidinsoluble ash as a natural marker in ruminant digestibility studies. J. Anim. Sci., 44(2):283-287.

ZOBELL, D.R., GOONEWARDENE, L.A., ENGSTROM, D.F., 1990. Potential of triticale as a feed for finishing heifers. Can. J. Anim. Sci., 70(1):325-328.

Recebido em: 20/09/99

Aceito em: 17/04/00 